\title{
The Structure and Function of Supported Molybdenum Nitride Hydrodenitrogenation Catalysts
}

\author{
Craig W. Colling and Levi T. Thompson \\ Department of Chemical Engincering. The University of Michigan. Ann Arbor, Michigan 48109-2136
}

Received July 27, 1993; revised September 29. 1993

\begin{abstract}
A series of $\gamma-\mathrm{Al}_{2} \mathrm{O}_{3}$ supported Mo nitrides were prepared by the temperature programmed reaction of supported molybdates with $\mathrm{NH}_{3}$. Several loadings, heating rates, and space velocities were employed in an attempt to vary the properties of the nitride. The structure and composition of the supported nitrides depended on the structure of the precursor oxide and the conditions employed in nitriding the oxide. The ease with which the oxide was nitrided improved with increasing Mo loading. Nitride domains in the lowloaded materials ( 4 and $8 \mathrm{wt} \% \mathrm{Mo}$ ) were highly dispersed and $\mathrm{X}$ ray amorphous while the higher-loaded catalysts (16 wt\% Mo) consisted of $\gamma-\mathrm{Mo}_{2} \mathrm{~N}$ crystallites. The response of the high-loaded materials to the various nitriding conditions was similar to that observed for unsupported $\gamma-\mathrm{Mo}_{2} \mathrm{~N}$. The supported Mo nitrides were active for the hydrodenitrogenation of pyridine. In fact, their activities were superior to that of a commercial sulfided $\mathrm{Ni}-\mathrm{Mo}$ hydrotreating catalyst and comparable to those of the unsupported Mo nitrides. The catalytic properties of the supported Mo nitrides depended on the size and composition of the Mo nitride domains. We believe that the most active sites were located at the perimeters of two-dimensional, raft-like domains. Regions near the perimeter also appeared to be nitrogen deficient. Lower activity sites were associated with the $\gamma-\mathrm{Mo}_{2} \mathrm{~N}$ crystallite surfaces. 1994 Academic Press, Inc.
\end{abstract}

\section{INTRODUCTION}

Molybdenum nitrides are active and selective catalysts for hydrodenitrogenation (1-5) and hydrodesulfurization (6-8). Typically, the predominant phase in Mo nitride catalysts is $\gamma-\mathrm{Mo}_{2} \mathrm{~N}$. The Mo atoms in $\gamma-\mathrm{Mo}_{2} \mathrm{~N}$ are arranged in a face-centered cubic array, with nitrogen atoms randomly distributed in half of the octahedral interstices. These interstices may also be filled with other atoms such as carbon or oxygen. Molybdenum nitrides can be prepared in high surface area form via the temperature programmed reaction (TPR) of $\mathrm{MoO}_{3}$ with $\mathrm{NH}_{3}$. This technique involves carrying out the gas-solid reaction as the temperature is increased linearly with time. We found that the compositions, structures, and hydrodenitrogenation (HDN) activities of unsupported Mo nitrides were strong functions of the heating rates and space velocities em- ployed (1). In addition, their catalytic properties were superior to those of a commercial sulfided Co-Mo hydrotreatment catalyst. A key observation from this study was that the activity decreased with increasing surface area. In fact, the highest surface area nitride had the lowest specific activity while the lowest surface area material had the highest activity. This was taken as evidence that HDN was structure-sensitive over the Mo nitrides. It also suggested that an effective catalyst could be prepared by reproducing the structures and stoichiometries present in the high activity nitrides on the surface of a high surface area support. To this end we prepared a series of supported Mo nitrides with different loadings using the TPR technique. Several different heating rates and space velocities were employed in an attempt to vary the properties of the nitride.

In this paper we discuss the preparation and the structural, compositional, chemisorptive, and catalytic properties of $\gamma-\mathrm{Al}_{2} \mathrm{O}_{3}$ supported Mo nitrides. We also describe the structural and chemical character of the catalytically active species in these materials.

\section{EXPERIMENTAL}

\section{Catalyst Preparation}

A series of alumina-supported molybdates with nominal loadings of 4 and $8 \mathrm{wt} \%$ Mo were prepared using the incipient wetness method. A solution of ammonium heptamolybdate, $\left(\mathrm{NH}_{4}\right)_{6} \mathrm{Mo}_{7} \mathrm{O}_{24} \cdot 4 \mathrm{H}_{2} \mathrm{O}$ (Mallinckrodt), in deionized water was added dropwise at room temperature to precalcined $\left(773 \mathrm{~K}, 5 \mathrm{~h}\right.$, dry air) $\gamma-\mathrm{Al}_{2} \mathrm{O}_{3}$ (Johnson Matthey, activated acidic, $96 \%$ metals basis, 60 mesh, 190 $\mathrm{m}^{2} / \mathrm{g}$ ). The materials were then calcined for $5 \mathrm{~h}$ at $773 \mathrm{~K}$ in dry air. Loadings beyond $\approx 10 \mathrm{wt} \%$ Mo could not be accomplished using this method, therefore equilibrium adsorption was used to prepare $\gamma-\mathrm{Al}_{2} \mathrm{O}_{3}$ supported molybdates with loadings of $16 \mathrm{wt} \% \mathrm{Mo}$. The method of preparation does not appear to have a significant effect on the character of the calcined supported molybdate (9); thus comparisons of materials produced using different prepar- 
TABLE 1

Summary of the Conditions Used to Synthesize the Supported Mo Nitrides

\begin{tabular}{lccrc}
\hline $\begin{array}{c}\text { Catalyst } \\
\text { code }\end{array}$ & $\begin{array}{c}\text { Loading } \\
\text { (wt\% Mo) }\end{array}$ & $\begin{array}{c}\text { MHSV } \\
(1 / \mathrm{h})\end{array}$ & $\begin{array}{c}\beta_{1} \\
(\mathrm{~K} / \mathrm{h})\end{array}$ & $\begin{array}{c}\beta_{2} \\
(\mathrm{~K} / \mathrm{h})\end{array}$ \\
\hline MN04+++ & 4.2 & $17(+)$ & $100(+)$ & $200(+)$ \\
MN04+-+ & 4.2 & $17(+)$ & $40(-)$ & $200(+)$ \\
MN04-++ & 4.2 & $8.5(-)$ & $100(+)$ & $200(+)$ \\
MN08+++ & 8.4 & $17(+)$ & $100(+)$ & $200(+)$ \\
MN08+-+ & 8.3 & $17(+)$ & $40(-)$ & $200(+)$ \\
MN08-++ & 8.4 & $8.5(-)$ & $100(+)$ & $200(+)$ \\
MN16+++ & 16 & $17(+)$ & $100(+)$ & $200(+)$ \\
MN16+-+ & 16 & $17(+)$ & $40(-)$ & $200(+)$ \\
MN16+-- & 16 & $17(+)$ & $40(-)$ & $100(-)$ \\
\hline
\end{tabular}

ative techniques should not be compromised. The parameters used to prepare the $16 \mathrm{wt} \%$ Mo materials were similar to those employed by Wang and Hall (10). A $0.007 M$ solution of $\left(\mathrm{NH}_{4}\right)_{6} \mathrm{Mo}_{7} \mathrm{O}_{24} \cdot 4 \mathrm{H}_{2} \mathrm{O}$ in deionized water was prepared and adjusted to $\mathrm{pH}=1.1$ using $\mathrm{HNO}_{3} \cdot \gamma-\mathrm{Al}_{2} \mathrm{O}_{3}$ $(10 \mathrm{~g})$ was then added to this solution and stirred for $96 \mathrm{~h}$. The solution was filtered and the resulting cake was dried at $373 \mathrm{~K}$ for $60 \mathrm{~min}$ and then ground with a mortar and pestle. Finally, the materials were calcined at $773 \mathrm{~K}$ for $5 \mathrm{~h}$ in dry air.

The nitrides were prepared by reacting the supported molybdates with $\mathrm{NH}_{3}$ using different molar hourly space velocities (MHSV) and heating rates (see Table.1). The experimental parameters and their values were chosen to match those employed in our previous work. The experiments were carried out using $\mathrm{NH}_{3}$ (Scott, 99.998\%) flowing at $150 \mathrm{~cm}^{3} / \mathrm{min}$. The temperature program consisted of four segments: rapid heating from room temperature to $623 \mathrm{~K}$ in $30 \mathrm{~min}$, heating from 623 to $723 \mathrm{~K}$ at a rate $\left(\beta_{1}\right)$ of $40(-)$ or $100(+) \mathrm{K} / \mathrm{h}$, heating from 723 to $973 \mathrm{~K}$ at a rate $\left(\beta_{2}\right)$ of $100(-)$ or $200(+) \mathrm{K} / \mathrm{h}$, and soaking at $973 \mathrm{~K}$ for $60 \mathrm{~min}$. The materials were cooled to room temperature in $\mathrm{NH}_{3}$, then passivated with $1 \% \mathrm{O}_{2}$ in $\mathrm{He}$ (Scott) for $2 \mathrm{~h}$ to inhibit bulk reoxidation. We used a code to distinguish the materials: $\mathrm{MN} x x y y y$, where $x x$ is the nominal Mo loading in wt\%, and yyy signifies the nitridation conditions. For example, MN16+++ denotes the 16 wt\% Mo loaded nitride prepared using $\beta_{1}=100 \mathrm{~K} / \mathrm{h}$, $\beta_{2}=200 \mathrm{~K} / \mathrm{h}$, and $\mathrm{MHSV}=17 \mathrm{~h}^{-1}$.

\section{$X$-Ray Diffraction}

The crystalline structures were determined using X-ray diffraction (XRD). The diffraction patterns were collected using a Rigaku DMAX-B diffractometer and $\mathrm{CuK \alpha}$ radiation $(\lambda=1.542 \AA)$. Data acquisition, peak identification, and data plotting were accomplished using a Gateway
$2000486 / 33 \mathrm{C}$ interfaced to the diffractometer. Average crystallite sizes, $d_{c}$, were estimated using the Scherrer equation (11),

$$
d_{\mathrm{c}}=\frac{K \lambda}{B \cos \theta}
$$

where $K$ is a constant (taken here to be 0.9 ), $\lambda$ is the $\mathrm{X}$ ray radiation wavelength, $B$ is the corrected peak width, and $\theta$ is the Bragg angle of the diffraction peak. The peak width was taken as the full width at half maximum intensity of the most intense peak assigned to the particular phase.

\section{Composition Analysis}

Neutron activation analysis (NAA) was used to determine the bulk compositions. The samples were bombarded with thermal neutrons and the emitted radiation was analyzed as the resulting radioisotopes decayed. Neutron activation analysis was effective for measuring the concentrations of Mo and Al. Unfortunately, the abundant isotopes of nitrogen and oxygen activate to form isotopes which do not produce $\gamma$-radiation during decay. The NAA was performed at the University of Michigan Ford Nuclear Reactor in the Phoenix Memorial Laboratory. Approximately $200 \mathrm{mg}$ of material was placed in a polyethylene tube for analysis. Aluminum activated easily (12), producing an isotope with a half-life of $2.246 \mathrm{~min}$ and radiation at $1778.8 \mathrm{keV}$. Molybdenum activated more slowly, producing an isotope with a half-life of $66.02 \mathrm{~h}$ that gave decay features chiefly at $140.5 \mathrm{keV}$. The samples were first activated for $1 \mathrm{~min}$, allowed to decay for 25 min, and counted for $12 \mathrm{~min}$. This analysis was used to quantify the $\mathrm{Al}$ content. The materials were then activated in the reactor core for $1 \mathrm{~h}$, and counted after 1-2 days. This procedure permitted selective measurement of the Mo content. We used NBS-SRM-1663A as a standard for $\mathrm{Al}$ (trace elements in coal fly ash containing $14.3 \% \mathrm{Al}$ ) and NBS-SRM-330 for Mo (copper ore mill heads containing $0.018 \% \mathrm{Mo}$ ).

The bulk nitrogen, carbon, and hydrogen contents were measured for the as-prepared, degassed, and spent catalysts using a Perkin-Elmer 2400 CHN Elemental Analyzer. The as-prepared supported Mo nitrides were degassed by heating them from room temperature to $773 \mathrm{~K}$ at $15 \mathrm{~K} / \mathrm{min}$ in $30 \mathrm{~cm}^{3} / \mathrm{min}$ of Ar. During elemental analysis, between 2 and $6 \mathrm{mg}$ of material was combusted in 2 atm of $\mathrm{O}_{2}$ at $1300 \mathrm{~K}$. Nitrogen oxide combustion products were reduced over copper at $915 \mathrm{~K}$ and the resulting $\mathrm{N}_{2}, \mathrm{H}_{2} \mathrm{O}$, and $\mathrm{CO}_{2}$ compositions were measured using a thermal conductivity detector. The instrument was calibrated with acetanilide following the manufacturer's specifications. The analyses were repeated using varying amounts of materials to insure complete combustion. $\mathrm{Ni}$ - 
trogen, carbon, and hydrogen contents were reproducible to $\pm 0.2 \mathrm{wt} \%$ for each.

\section{Sorption Analysis}

The BET surface areas and $\mathrm{O}_{2}$ uptakes of the catalysts were measured using a Quantasorb Sorption Analyzer (Model QS-17). For both analyses, the as-prepared materials were heated to $673 \mathrm{~K}$ in $\mathrm{H}_{2}(99.99 \%$, Air Products) flowing at $20 \mathrm{~cm}^{3} / \mathrm{min}$ and held there for $3 \mathrm{~h}$, then cooled to room temperature in flowing $\mathrm{He}$. Standard BET surface area measurements used a mixture of $29.3 \% \mathrm{~N}_{2}$ in $\mathrm{He}$ (Scott) as the adsorbate gas. Accurately measured pulses $( \pm 2 \%)$ of $\mathrm{N}_{2}(99.998 \%$, Air Products) were used to calibrate the instrument.

For $\mathrm{O}_{2}$ chemisorption, the samples were placed in a dry ice/acetone bath at $195 \mathrm{~K}$ after reduction. The experiments were carried out at $195 \mathrm{~K}$ in a dynamic fashion to avoid corrosive chemisorption (13, 14). An appropriate amount of $9.98 \% \mathrm{O}_{2}$ in $\mathrm{He}$ (Scott) was then injected into a flowing stream of $\mathrm{He}$ and passed over the sample. The $\mathrm{O}_{2}$ that was not adsorbed was detected and recorded. When the $\mathrm{O}_{2}$ peaks reached essentially constant area, the surface was assumed to be saturated. The amount of $\mathrm{O}_{2}$ adsorbed was calculated from the number of injections and the peak areas. The $\mathrm{O}_{2}$ uptakes were reproducible to within $\pm 3 \mu \mathrm{mol} / \mathrm{g}$.

\section{Catalytic Properties}

The catalytic properties were measured using a 6.35 mm OD Pyrex reactor. Approximately $0.2 \mathrm{~g}$ of catalyst were placed on top of a glass wool plug and heated to 673 $\mathrm{K}$ at $2 \mathrm{~K} / \mathrm{min}$ in flowing $\mathrm{H}_{2}$. The catalysts were held at $673 \mathrm{~K}$ for at least $12 \mathrm{~h}$, then cooled to the reaction temperature. Between measurements, the catalysts were held at $673 \mathrm{~K}$ for at least $12 \mathrm{~h}$ in flowing $\mathrm{H}_{2}$. A stream of $\mathrm{H}_{2}$ (99.99\%, Air Products) flowing at $20 \mathrm{~cm}^{3} / \mathrm{min}$ was bubbled through a pool of pyridine (Aldrich, anhydrous, $99+\%)$ at $273 \mathrm{~K}$ and passed over the catalyst bed. The reactor effluent was analyzed using a Hewlett Packard $5890 \mathrm{~A}$ gas chromatograph equipped with a flame ionization detector and a Spectra Physics Integrator. The bed temperature was maintained using a programmable temperature controller (Omega $\mathrm{CN}-2010$ Series). The activities and selectivities were determined at 588,603,618, 633 , and $648 \mathrm{~K}$.

The catalytic properties of a commercial sulfided $\mathrm{Ni}-\mathrm{Mo} / \mathrm{Al}_{2} \mathrm{O}_{3}$ hydrotreating catalyst (Crosfield 504-K, $19 \% \mathrm{MoO}_{3}, 5.4 \% \mathrm{NiO}$, balance $\mathrm{Al}_{2} \mathrm{O}_{3}$ ) were also evaluated. First, the catalyst pellets were crushed and sieved to a $60 / 80$ mesh. The catalyst was heated from room temperature to $673 \mathrm{~K}$ at $2 \mathrm{~K} / \mathrm{min}$ in $20 \mathrm{~cm}^{3} / \mathrm{min}$ of $\mathrm{H}_{2}$, then sulfided for $4 \mathrm{~h}$ at $673 \mathrm{~K}$ in a mixture of $2 \% \mathrm{H}_{2} \mathrm{~S}$ in $\mathrm{H}_{2}$ flowing at $20 \mathrm{~cm}^{3} / \mathrm{min}$. These conditions approximate those typically used to pretreat commercial hydrotreating catalysts. We only wanted to provide a rough comparison of the catalytic properties of supported nitrides and sulfides; therefore we made no attempt to optimize the sulfides. Prior to the activity measurements the catalyst was reduced at $673 \mathrm{~K}$ for at least $12 \mathrm{~h}$ in $\mathrm{H}_{2}\left(20 \mathrm{~cm}^{3} / \mathrm{min}\right)$.

\section{RESULTS}

\section{$X$-Ray Diffraction/Elemental Analysis}

$X$-ray diffraction patterns of the $\gamma-\mathrm{Al}_{2} \mathrm{O}_{3}$ supported molybdates before and after nitridation are given in Fig. 1. The only discernible peaks in the patterns for the 4 and $8 \%$ loaded oxides were due to $\gamma-\mathrm{Al}_{2} \mathrm{O}_{3}$. Monolayer coverage by $\mathrm{MoO}_{3}$ on a material with $190 \mathrm{~m}^{2} / \mathrm{g}$ would correspond to a loading of $\approx 10 \mathrm{wt} \% \mathrm{Mo}$. The absence of peaks other than those for $\gamma-\mathrm{Al}_{2} \mathrm{O}_{3}$ suggested that the Mo oxide domains on the surfaces of the low loaded catalysts were small, highly dispersed, and/or amorphous. Similar results have been described previously and attributed to the difficulty in detecting small, highly dispersed particles using XRD (15). Diffraction peaks due to $\mathrm{MoO}_{3}$ and $\gamma-\mathrm{Al}_{2} \mathrm{O}_{3}$ were clearly visible in the patterns for the $16 \%$ material. There was no evidence of any other crystalline species in these materials. The average $\mathrm{MoO}_{3}$ crystallite size for the high loaded material was $372 \AA$ (calculated using the $\mathrm{MoO}_{3}(021)$ reflection).

Nitridation of the 4 and $8 \%$ materials did not significantly change their diffraction patterns (see Fig. 1c). The diffraction patterns for the $16 \%$ materials prepared using different nitriding schemes indicated the presence of crystalline $\gamma-\mathrm{Mo}_{2} \mathrm{~N}$. A typical pattern is given in Fig. 1b. There was no evidence of unreacted Mo oxides and no nitrides other than $\gamma-\mathrm{Mo}_{2} \mathrm{~N}$ were produced. Under conditions similar to those used in this work, $\gamma-\mathrm{Mo}_{2} \mathrm{~N}$ was the only nitride produced during the temperature programmed nitridation of bulk $\mathrm{MoO}_{3}(5,6,16)$. One difference between the supported and unsupported nitrides was the degree of texturing. No texturing was observed for the supported crystallites, while crystallites in the unsupported materials were plate-like. The $\gamma-\mathrm{Mo}_{2} \mathrm{~N}$ crystallites in the $16 \%$ materials were much smaller than the $\mathrm{MoO}_{3}$ crystallites in the precursor oxide. Furthermore, the crystallite size varied depending on the nitriding conditions employed. The average $\gamma-\mathrm{Mo}_{2} \mathrm{~N}$ crystallite sizes for $\mathrm{MN} 16+++$, $\mathrm{MN} 16+-+$, and $\mathrm{MN} 16+--$ were 89,79 , and $53 \AA$, respectively (using the $\gamma-\mathrm{Mo}_{2} \mathrm{~N}$ (200) reflection). Increasing the first or second heating rate caused the nitride crystallite size to increase.

The bulk compositions of the as-prepared supported Mo nitrides are given in Table 2. The Mo loadings measured for the 4 and $8 \%$ materials were similar to those estimated based on the precursor concentrations used during impregnation. The Mo loadings for the $16 \%$ materi- 


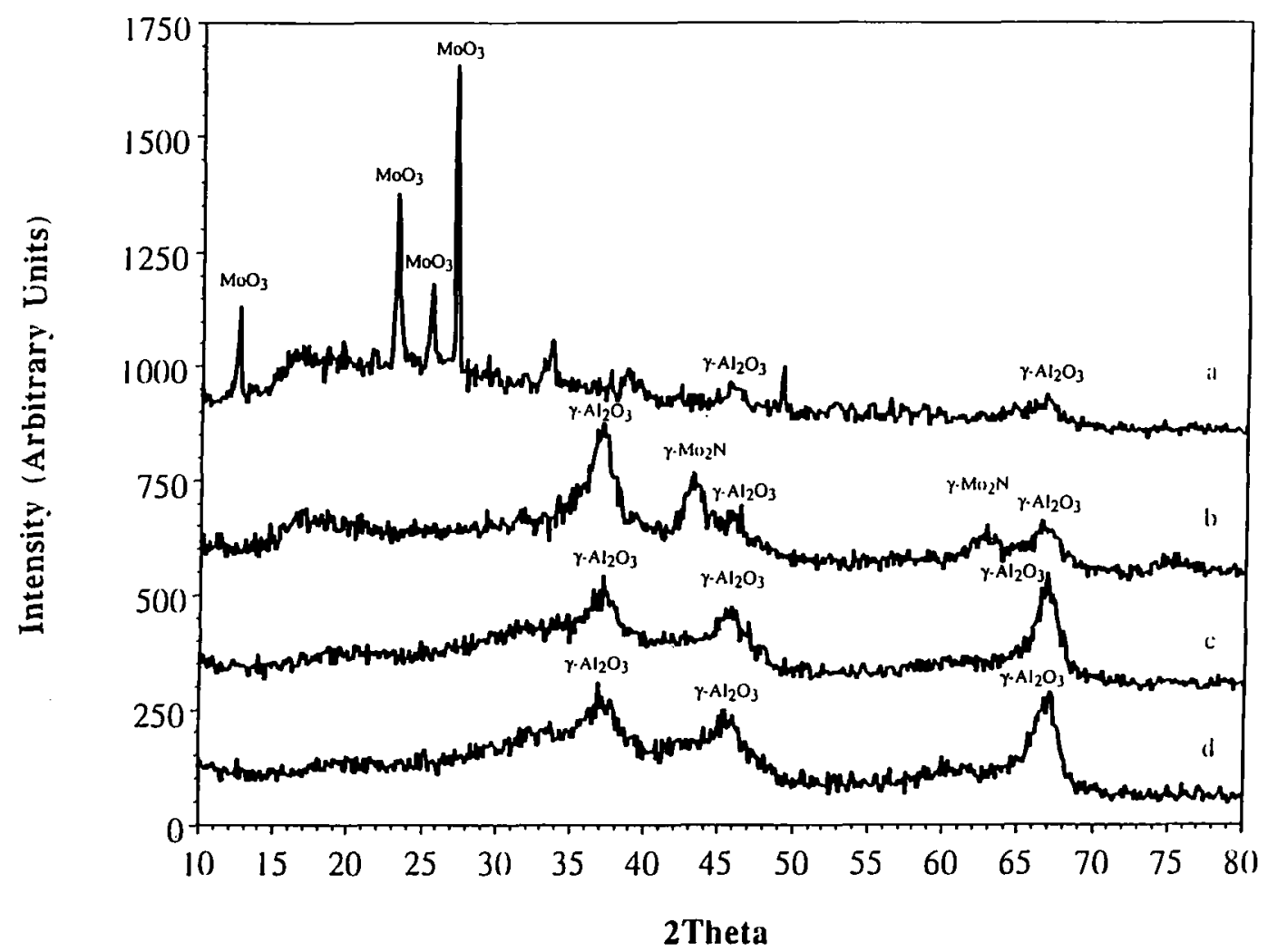

FIG. 1. X-ray diffraction patterns of (a) the $16 \% \mathrm{Mo} \gamma-\mathrm{Al}_{2} \mathrm{O}_{3}$ supported molybdate, (b) $\mathrm{MN} 16+++$, (c) $\mathrm{MN} 04+++$, and (d) the $\gamma-\mathrm{Al}_{2} \mathrm{O}_{3}$ support.

als were consistent with those expected based on reports by Wang and Hall (10). We nitrided blank $\gamma-\mathrm{Al}_{2} \mathrm{O}_{3}$ in a manner similar to that used to prepare the supported Mo nitride catalysts, and did not detect nitrogen in the resulting material (the minimum detection limit for nitrogen was $0.2 \mathrm{wt} \%$ ). This indicated that the nitrogen was associated with the presence of Mo and not $\gamma-\mathrm{Al}_{2} \mathrm{O}_{3}$. The nitrogen content for the as-prepared materials scaled with Mo loading. Some hydrogen was also detected in the as-prepared materials. The minimum detection limits for hydrogen and carbon were both $0.2 \mathrm{wt} \%$.

TABLE 2

Bulk Compositions of the As-Prepared Supported Mo Nitrides

\begin{tabular}{lcccc}
\hline $\begin{array}{c}\text { Catalyst } \\
\text { code }\end{array}$ & $\begin{array}{c}\text { Loading } \\
(\mu \mathrm{mol} \mathrm{Mo} / \mathrm{g})\end{array}$ & N/Mo & C/Mo & H/Mo \\
\hline MN04+++ & 440 & 0.77 & 0.00 & 3.0 \\
MN04+-+ & 440 & 0.79 & 0.00 & 2.4 \\
MN04-++ & 440 & 0.91 & 0.00 & 2.9 \\
MN08+++ & 880 & 0.87 & 0.00 & 1.1 \\
MN08+-+ & 870 & 0.68 & 0.00 & 0.72 \\
MN08-++ & 880 & 0.72 & 0.00 & 0.72 \\
MN16+++ & 1700 & 0.81 & 0.00 & 0.96 \\
MN16+-+ & 1700 & 0.81 & 0.00 & 0.78 \\
MN16+-- & 1700 & 0.89 & 0.00 & 1.1 \\
\hline
\end{tabular}

The N/Mo ratios for the as-prepared catalysts were intermediate between those expected for $\delta$-MoN and $\gamma$ $\mathrm{Mo}_{2} \mathrm{~N}$. Degassing the materials caused a significant loss of nitrogen and hydrogen (see Table 3). It was apparent that $\mathrm{NH}_{3}$ desorbed from the materials during degassing, as indicated by the near $3: 1$ ratio for the hydrogen loss relative to the nitrogen loss. This $\mathrm{NH}_{3}$ was probably residue from the synthesis. Nitrogen left after degassing was considered to be a constituent of the nitride phase. The hydrogen loss for the $4 \%$ catalysts was greater than that expected if the hydrogen loss was due solely to $\mathrm{NH}_{3}$

TABLE 3

Bulk Compositions of the Degassed Supported Mo Nitrides

\begin{tabular}{lccc}
\hline Catalyst code & N/Mo & C/Mo & H/Mo \\
\hline MN04+++ & 0.10 & 0.06 & 0.00 \\
MN04+-+ & 0.03 & 0.00 & 0.00 \\
MN04-++ & 0.12 & 0.00 & 0.00 \\
MN08+++ & 0.26 & 0.00 & 0.00 \\
MN08+-+ & 0.20 & 0.01 & 0.00 \\
MN08-++ & 0.14 & 0.00 & 0.00 \\
MN16+++ & 0.29 & 0.00 & 0.30 \\
MN16+-+ & 0.34 & 0.01 & 0.00 \\
MN16+-- & 0.36 & 0.02 & 0.00 \\
\hline
\end{tabular}


TABLE 4

Bulk Compositions of Spent Supported Mo Nitrides

\begin{tabular}{llll}
\hline Catalyst code & N/Mo & C/Mo & H/Mo \\
\hline MN04+++ & 0.55 & 1.8 & 0.24 \\
MN04+-+ & 0.60 & 1.8 & 0.36 \\
MN04-++ & 0.43 & 1.9 & 0.96 \\
MN08+++ & 0.42 & 0.71 & 0.24 \\
MN08+-+ & 0.33 & 0.60 & 0.36 \\
MN08-++ & 0.45 & 1.2 & 0.60 \\
MN16+++ & 0.27 & 0.29 & 0.18 \\
MN16+-+ & 0.47 & 0.28 & 0.00 \\
MN16+-- & 0.51 & 0.24 & 0.00 \\
\hline
\end{tabular}

desorption. This observation suggested that hydrogen was present in the Mo-containing phase. If the hydrogen was from adsorbed $\mathrm{H}_{2} \mathrm{O}$ the response would not have depended on loading. The N/Mo ratios for the degassed catalysts were lower than those expected for $\gamma-\mathrm{Mo}_{2} \mathrm{~N}$, the crystalline phase identified in the high-loaded material. This implied that the materials contained $\mathrm{Mo}$ and $\gamma-\mathrm{Mo}_{2} \mathrm{~N}$, or substoichiometric $\gamma-\mathrm{Mo}_{2} \mathrm{~N}$. There was no evidence of Mo metal in any of the materials. The fact that the N/Mo ratio was outside the stoichiometric limits given in the $\mathrm{Mo}: \mathrm{N}$ phase diagram for $\gamma-\mathrm{Mo}_{2} \mathrm{~N}$ indicated that other nonmetal atoms or vacancies were present in the lattice. One possible occupant is oxygen from the precursor or from the support.

The nitrides were stable under the chemisorption $(300$ $\mathrm{K}$ in $\mathrm{O}_{2} / \mathrm{He}$ ) and reaction conditions (up to $673 \mathrm{~K}_{\text {in }} \mathrm{H}_{2}$ / pyridine). Diffraction patterns of the materials after measurement of their chemisorptive and catalytic properties were similar to those of the as-prepared materials; however, the elemental compositions were very different (see Table 4). In addition to nitrogen, significant amounts of carbon were present in the materials following exposure to the pyridine HDN conditions. While the N/Mo ratios were constant at $\approx 0.45$, the $\mathrm{C} / \mathrm{Mo}$ ratio decreased markedly with increasing loading but did not vary with changes in the nitriding conditions. The N/Mo ratio partially reflects the presence of $\mathrm{NH}_{3}$ adsorbed at the surface.

\section{Sorption Analysis}

The BET surface areas of the supported nitrides were slightly lower than that of the blank $\gamma-\mathrm{Al}_{2} \mathrm{O}_{3}$ and ranged from 115 to $140 \mathrm{~m}^{2} / \mathrm{g}$. The surface area and oxygen chemisorption results are summarized in Table 5. Oxygen did not chemisorb onto the pretreated $\gamma-\mathrm{Al}_{2} \mathrm{O}_{3}$. The influences of the Mo loading and nitriding conditions on the chemisorptive properties are illustrated in Fig. 2. The $\mathrm{O}_{2}$ uptake increased linearly with loading up to $\approx 1000 \mu \mathrm{mol} \mathrm{Mo} /$ $\mathrm{g}_{\mathrm{cat}}$. For materials prepared using the $(+-+)$ nitriding scheme, the $\mathrm{O}_{2}$ uptake continued to increase linearly beyond the Mo loading expected to produce monolayer molybdate coverage $\left(\approx 1000 \mu \mathrm{mol} \mathrm{Mo} / \mathrm{g}_{\text {cat }}\right)$. While the general trends were similar for materials prepared using the $(+++)$ nitriding scheme, the $\mathrm{O}_{2}$ uptake leveled somewhat at the higher loadings. The increase in $\mathrm{O}_{2}$ uptake with loading was not as dramatic for the materials prepared using the low space velocity $(-++)$ as with the other materials.

The influence of the nitriding conditions depended on the Mo loading. When comparing materials with loadings of 4 or $8 \% \mathrm{Mo}$, the $\mathrm{O}_{2}$ uptake increased with increasing space velocity or first heating rate; however, a different behavior was observed for the $16 \%$ loaded materials. For these materials the amount of chemisorbed $\mathrm{O}_{2}$ decreased when the first heating rate was increased or the second heating rate was decreased.

\section{Catalytic Properties}

The pyridine HDN reaction rates steadied within the first $15 \mathrm{~min}$ on stream and remained constant for several hours on stream. The specific rates were reproducible to within $\pm 15 \%$. Minimal changes in the reaction rate were observed when the reactant flow rate was varied indicating an absence of external mass transport limitations.

Arrhenius plots of the HDN activities are given in Figs. 3 and 4 . The steady-state activities of the $4 \%$ catalysts were consistently higher than those of the $8 \%$ and $16 \% \mathrm{Mo}$ loaded catalysts. This suggested that the active species in the $4 \%$ catalysts were different from those in the higher loaded catalysts. The apparent activation energies for the supported materials were similar to those determined for bulk $\gamma-\mathrm{Mo}_{2} \mathrm{~N}$ (1).

Typical HDN product distributions for the supported Mo nitride catalysts are given in Fig. 5 along with product distributions for the sulfided $\mathrm{Ni}-\mathrm{Mo} / \mathrm{Al}_{2} \mathrm{O}_{3}$ and unsupported molybdenum nitride catalysts. All of the catalysts

\section{TABLE 5}

Summary of the Sorption Analyses

\begin{tabular}{lccc}
\hline $\begin{array}{c}\text { Catalyst } \\
\text { code }\end{array}$ & $\begin{array}{c}\text { Loading } \\
(\mu \mathrm{mol} \mathrm{Mo} / \mathrm{g})\end{array}$ & $\begin{array}{c}\text { Surface area } \\
\left(\mathrm{m}^{2} / \mathrm{g}\right)\end{array}$ & $\begin{array}{c}\text { Uptake }^{a} \\
(\mu \mathrm{mol} \mathrm{O} / \mathrm{g})\end{array}$ \\
\hline MN04+++ & 440 & 133 & 18 \\
MN04+-+ & 440 & 115 & 14 \\
MN04-++ & 440 & 137 & 12 \\
MN08+++ & 880 & 136 & 39 \\
MN08+-+ & 870 & 127 & 37 \\
MN08-++ & 880 & 140 & 21 \\
MN16+++ & 1700 & 124 & 53 \\
MN16+-+ & 1700 & 139 & 79 \\
MN16+-- & 1700 & 132 & 110 \\
\hline
\end{tabular}

\footnotetext{
${ }^{a}$ Measured at $195 \mathrm{~K}$.
} 


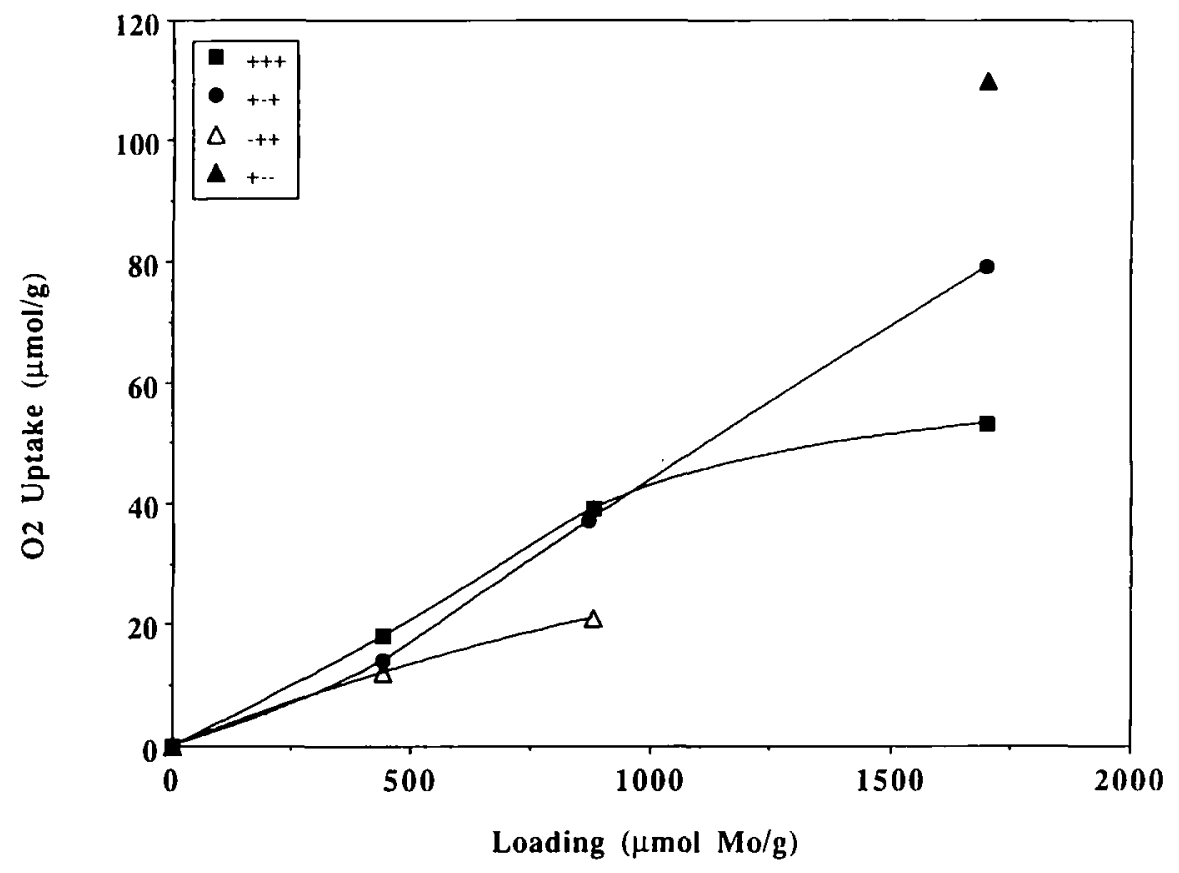

FIG. 2. The effects of loading and nitriding conditions on the $\mathrm{O}_{2}$ uptakes of the supported Mo nitrides.

favored the production of alkanes with pentane being the predominant product. The product distributions for the supported Mo nitrides were similar and were not significantly affected by the nitridation conditions.

The kinetic parameters are given in several different ways in Table 6. By every measure the supported nitrides were more active than the sulfided $\mathrm{Ni}-\mathrm{Mo} / \mathrm{Al}_{2} \mathrm{O}_{3}$ catalyst and of similar activity as the unsupported nitrides. Note that the activities on a total Mo basis paralleled those on an oxygen uptake basis. When the supported Mo nitride

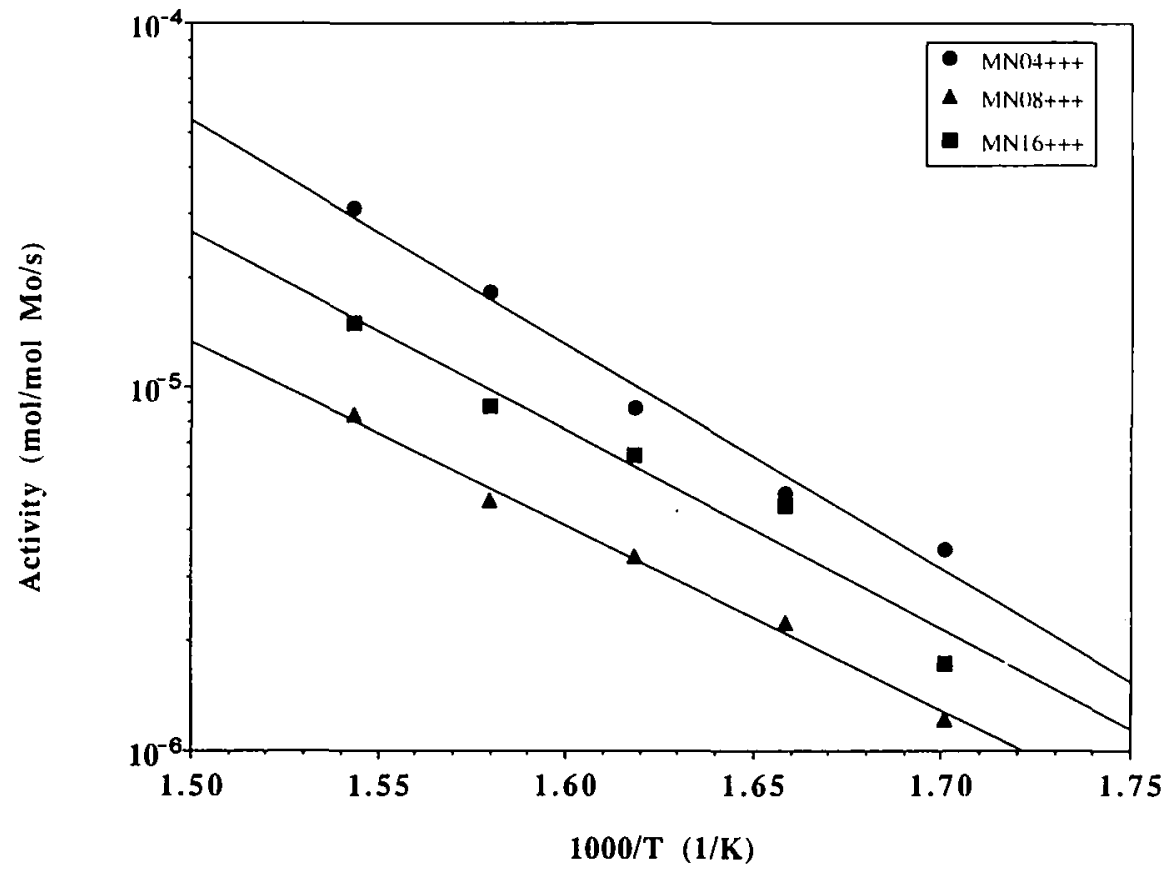

FIG. 3. Arrhenius plot of the activities for the Mo nitride catalysts prepared using the $(+++)$ nitriding scheme. 


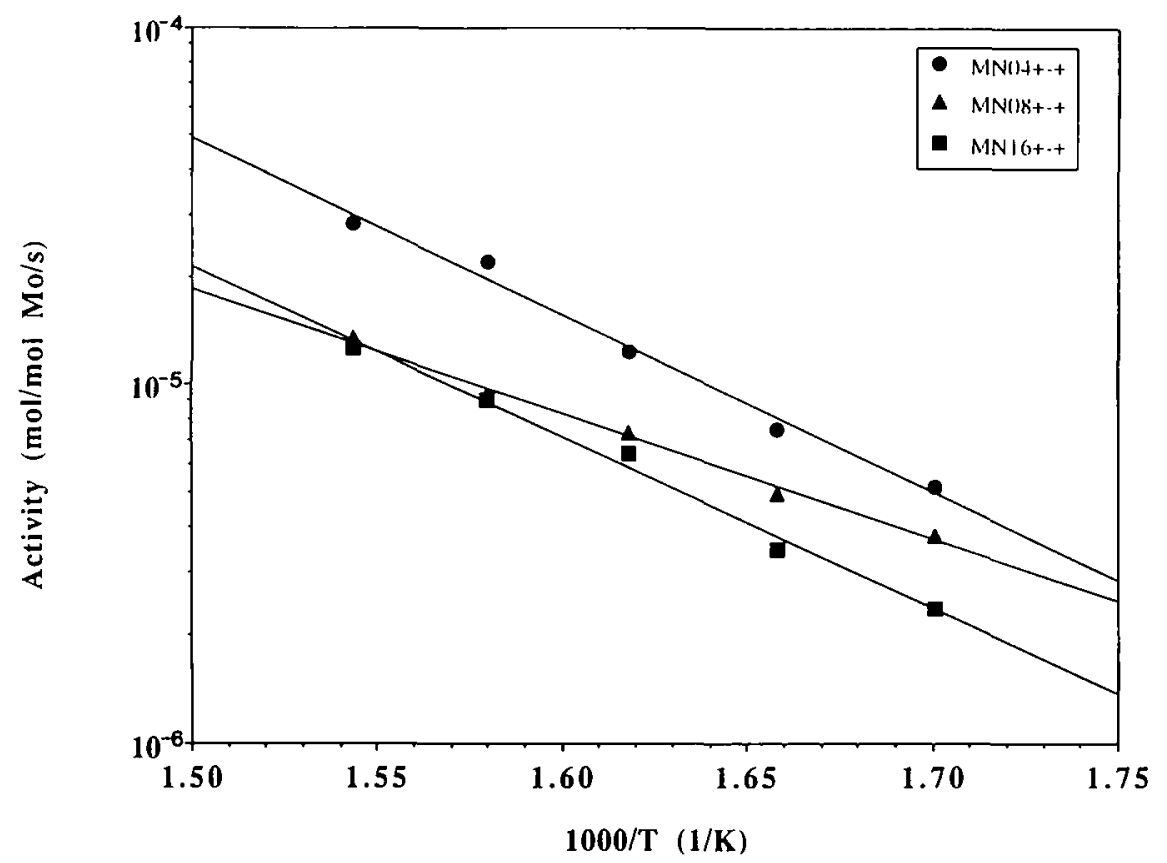

FIG. 4. Arrhenius plot of the activities for the Mo nitride catalysts prepared using the $(+-+)$ nitriding scheme.

catalysts prepared using the same nitriding conditions were compared, the activities of the $4 \%$ catalysts were higher than those of the higher-loaded catalysts. The nitriding conditions also had an effect on the activity. For the 4 and $8 \%$ Mo loaded catalysts, increasing the space velocity or first heating rate caused a decrease in the activity. For the $16 \%$ catalysts, an increase in the first or second heating rate caused an increase in the activity. The influence of the synthesis parameters on the catalytic properties for these high loaded Mo nitride catalysts was

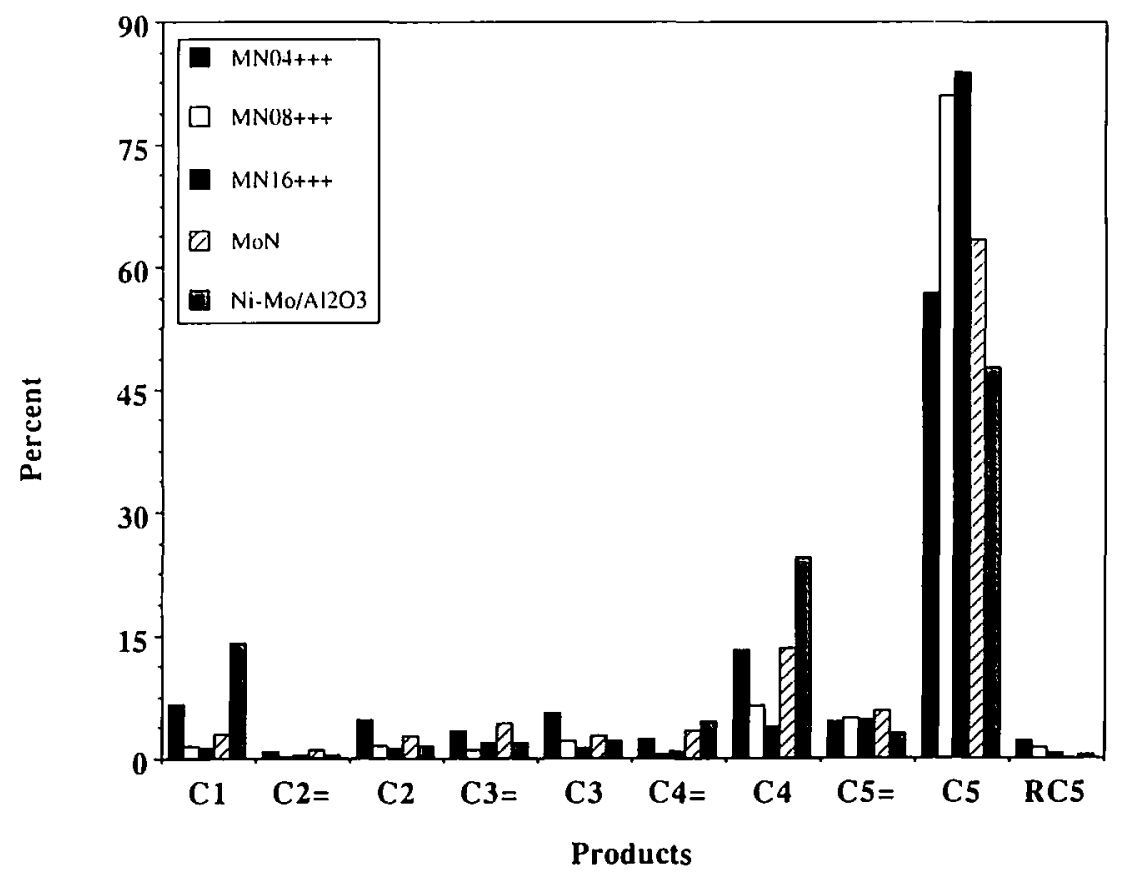

FIG. 5. Typical pyridine hydrodenitrogenation product distributions for selected supported Mo nitride catalysts, the sulfided hydrotreating catalyst, and an unsupported Mo nitride. Note that $\mathrm{C} n$ represents an $n$ carbon alkane, $\mathrm{C} n=$ represents an $n$ carbon alkene, and $\mathrm{RCS}$ represents cyclopentane. 
TABLE 6

Pyridine Hydrodenitrogenation Results

\begin{tabular}{|c|c|c|c|c|}
\hline \multirow{2}{*}{$\begin{array}{l}\text { Cataly'st } \\
\text { code }\end{array}$} & \multirow{2}{*}{$\begin{array}{l}\text { Reaction rate } \\
\text { (nmol/gat } / \mathrm{s})\end{array}$} & \multicolumn{2}{|c|}{ Activity $^{\lrcorner}$} & \multirow{2}{*}{$\frac{t_{\mathrm{acl}}}{\mid \mathrm{kca}] / \mathrm{mol})}$} \\
\hline & & $(\mu \mathrm{mol} / \mathrm{mol} \mathrm{Mo} / \mathrm{s})$ & $\left(\mu \mathrm{mol} / \mathrm{mol} \mathrm{O} \mathrm{O}_{2} / \mathrm{s}\right)$ & \\
\hline $\mathrm{MN} 04+++$ & 7.6 & 18 & 430 & 28 \\
\hline $\mathrm{MNO4}+-+$ & 9.2 & 22 & 640 & 23 \\
\hline $\mathrm{MN} 04-++$ & 6.0 & 14 & $500)$ & 32 \\
\hline MNO8 +t+ & 4.0 & 4.8 & 100 & 23 \\
\hline $\mathrm{MN08+-+}$ & 7.8 & 9.4 & 490 & 16 \\
\hline MNO8-++ & 3.9 & 4.7 & 190 & 21 \\
\hline MNI6+++ & 14 & 8.4 & 260 & 25 \\
\hline MNI6+-+ & 14 & 8.4 & 180 & 22 \\
\hline MNI6+-- & 9.7 & 5.8 & 91 & 20 \\
\hline $\operatorname{MoN}\left(t++1^{h}\right.$ & 52 & 5.4 & 1201 & 20 \\
\hline $\operatorname{MoN}\left(+-+1^{b}\right.$ & 47 & .8 & 360 & 25 \\
\hline $\mathrm{Ni}-\mathrm{Mo} / \mathrm{Al}_{2} \mathrm{O}_{3}$ & 0.27 & 0.20 & 1.8 & - \\
\hline
\end{tabular}

Measured at $101 \mathrm{kPa}$ and $633 \mathrm{~K}$

${ }^{b}$ Unsupported Mo nitrides.

similar to that observed for the unsupported Mo nitrides (1). However, the activity trends for the low-loaded catalysts were very different from those for the unsupported Mo nitrides.

\section{DISCUSSION}

\section{Catalyst Structure and Composition}

The structure and composition of the supported nitrides depended on the structure of the precursor oxide, and the conditions employed in nitriding the oxide. It has been reported that a two-dimensional Mo oxide structure is formed on the surface of $\gamma-\mathrm{Al}_{2} \mathrm{O}_{3}$ supported materials that contain less than the amount of molybdate necessary to produce monolayer coverage, while three-dimensional $\mathrm{MoO}_{3}$ crystallites are generated when monolayer coverage is exceeded. The two-dimensional structures are believed to be the result of strong interactions between the molybdate and the $\gamma-\mathrm{Al}_{2} \mathrm{O}_{3}$ surface. A secondary consequence of this interaction is a difficulty in reducing or sulfiding the supported molybdate $(15,17)$. Results presented here implied difficulties in nitriding $\gamma-\mathrm{Al}_{2} \mathrm{O}_{3}$ supported molybdates.

The ease with which the oxide was nitrided improved with increasing loading, as indicated by the increase in N/Mo ratio. This suggested that the molybdate species present in the low-loaded materials interacted more strongly with the support than those present in the high-loaded materials. Our results are consistent with the 4 and $8 \mathrm{wt} \%$ loaded oxides $\left(0.2\right.$ and $\left.0.4 \times 10^{15} \mathrm{Mo} / \mathrm{cm}^{2}\right)$ consisting of two-dimensional molybdate domains. Domains in these low loaded materials remained highly dispersed and $\mathrm{X}$ ray amorphous following nitridation. The $16 \mathrm{wt} \%$ loaded catalyst $\left(0.8 \times 10^{15} \mathrm{Mo} / \mathrm{cm}^{2}\right)$ consisted of $\mathrm{MoO}_{3}$ crystallites which were nitrided to smaller $\gamma-\mathrm{Mo}_{2} \mathrm{~N}$ crystallites. Nitridation appeared to go to completion as there was No evidence of residual Mo oxide in any of the nitrided materials. The significant reduction in crystallite size was due primarily to the dramatic increase in density on going from the oxide $\left(\rho_{\mathrm{MoO}_{3}}=4.7 \mathrm{~g} / \mathrm{cm}^{3}\right)$ to the nitride $\left(\rho_{\mathrm{Mo}_{2} \mathrm{~N}}=9.5 \mathrm{~g} / \mathrm{cm}^{3}\right)(16)$. A similar reduction in crystallite size was observed when bulk $\mathrm{MoO}_{3}$ was nitrided to $\gamma-\mathrm{Mo}_{2} \mathrm{~N}(16,18)$. The response of the $16 \mathrm{wt} \%$ loaded material to the various nitriding conditions was also similar to that observed for bulk $\gamma-\mathrm{Mo}_{2} \mathrm{~N}$ (1).

Information concerning the structure of the supported material can be deduced from the chemisorption results. Previously we reported that the $\mathrm{O} / \mathrm{Mo}_{\text {surface }}$ ratio averaged 0.21 for a series of unsupported Mo nitrides with surface areas that varied by more than an order of magnitude (1). Using this stoichiometry, the dispersions for the low loaded materials were $\approx 40 \%$ for catalysts prepared using the high space velocity $(+++$ or +-+$)$ and $\approx 25 \%$ for catalysts prepared using the low space velocity $(-++)$. Dispersions for the $16 \%$ catalysts ranged from $30-65 \%$ depending on the nitriding conditions employed. The lower heating rates favored higher dispersion of the active species. Perhaps the lower heating rate permitted longer times for migration of the material and thus high dispersions. Note that the $\mathrm{O} / \mathrm{Mo}$ ratios for catalysts produced using the $(+-+)$ nitriding scheme were approximately constant over the entire range of loadings examined. In order for the $\mathrm{O} / \mathrm{Mo}$ ratio or dispersion to remain constant with loading, the particles must have been raftlike. Thus, for a given set of nitriding conditions, we considered that the increase in $\mathrm{O}_{2}$ uptake with loading was due to an increase in the lateral dimension of the particle.

\section{Effect of Composition on Chemisorptive Properties}

The predominant factor governing the amount of $\mathrm{O}_{2}$ chemisorbed was the Mo loading; however, the composition of the supported species had a modest effect on the chemisorptive properties. We emphasize that this was a secondary effect and was not as significant as the loading. Intuitively one would expect $\mathrm{O}_{2}$ to chemisorb onto metal sites; therefore the chemisorption capacity should decrease with increasing N/Mo. This was not the case. Changes in the amount of $\mathrm{O}_{2}$ chemisorbed $(\mathrm{O} / \mathrm{Mo})$ paralleled changes in the nitrogen content $(\mathrm{N} / \mathrm{Mo}$ ) measured for the degassed materials. There are at least two explanations for this observation. First, chemisorbed oxygen might interact directly with nitrogen. This would probably require dissociation of $\mathrm{O}_{2}$ on sites other than the surface nitrogen. The sequence of events could involve chemisorption and dissociation of $\mathrm{O}_{2}$ onto Mo sites followed by interaction of atomic oxygen with nitrogen at or near 


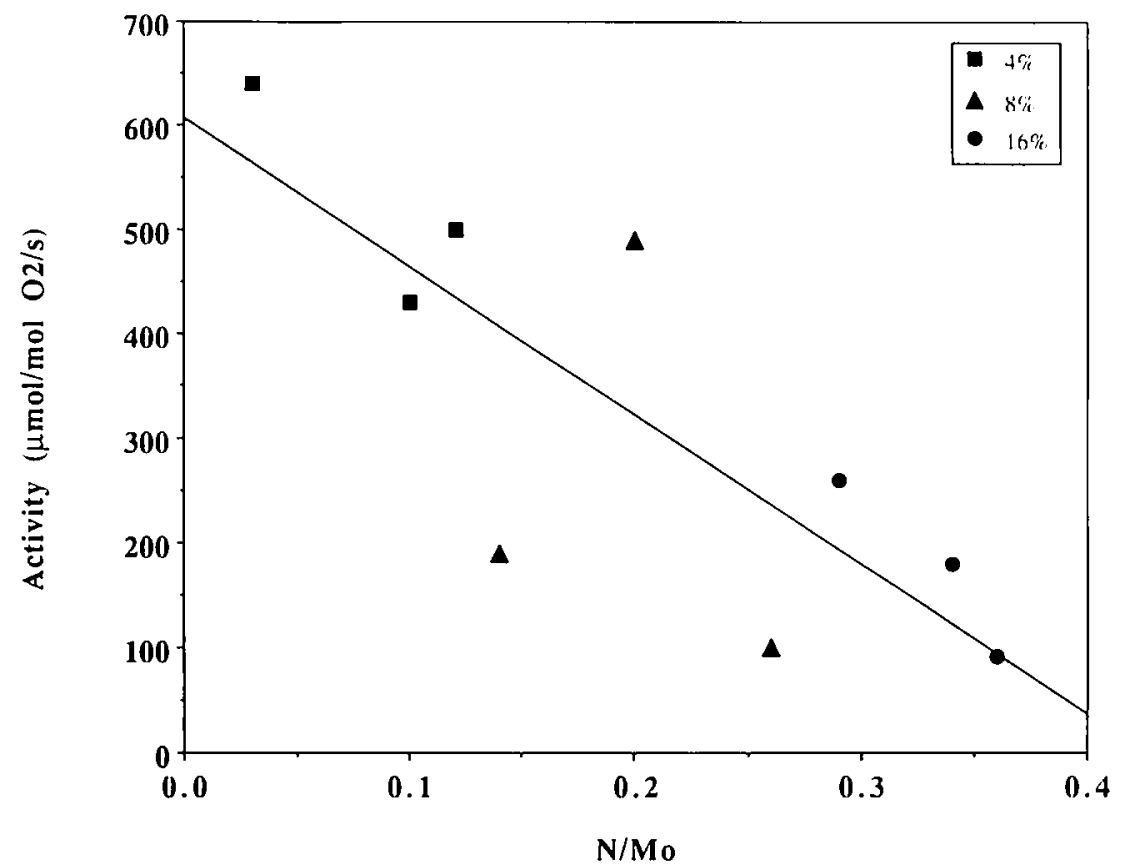

FIG. 6. The influence of loading and N/Mo ratio on the hydrodenitrogenation activities of the supported Mo nitrides.

the surface to produce a nitrosyl. Second, oxygen from the precursor oxide or support may have substituted for nitrogen vacant from the nitride lattice. Oxygen is more electronegative than nitrogen (19); therefore its presence should partially oxidize the Mo and inhibit the chemisorption of $\mathrm{O}_{2}$. Accordingly, as the degree of nitridation increases, the $\mathrm{O}_{2}$ chemisorption should increase. In any case, the results suggested that the nitride was highly dispersed; otherwise the bulk N/Mo ratio would not have had an influence on the chemisorption, a surface property.

\section{Effects of Structure and Composition on the Catalytic Properties}

The catalytic properties of the supported Mo nitrides appeared to depend on the size and composition of the Mo nitride domains. The effects of loading and N/Mo ratio are illustrated in Fig. 6. Recall that the trends were similar for activities on a Mo and $\mathrm{O}_{2}$ basis. The activity decreased then leveled off somewhat as the loading was increased. This indicated that the character of the active species varied with loading, and that pyridine HDN was structure-sensitive over the $\gamma-\mathrm{Al}_{2} \mathrm{O}_{3}$ supported Mo nitrides. Hydrodenitrogenation and hydrodesulfurization were also found to be structure-sensitive over unsupported Mo nitrides $(1,6)$.

We have concluded that there were two types of structures in the supported Mo nitrides: two-dimensional raftlike structures and $\gamma-\mathrm{Mo}_{2} \mathrm{~N}$ crystallites. The low-loaded nitrides appeared to consist primarily of raft-like structures while the high loaded materials contained $\gamma-\mathrm{Mo}_{2} \mathrm{~N}$ crystallites. The activity increased as the raftlike domain size decreased. For catalysts where $\gamma-\mathrm{Mo}_{2} \mathrm{~N}$ crystallites were identified, the activity increased with increasing crystallite size. In this respect the high-loaded supported Mo nitrides behaved like unsupported nitrides where the activity increased linearly with increasing particle size (1). The difference between the activities of the highloaded supported and the unsupported Mo nitride catalysts was probably due to differences in their particle sizes. Active sites in the unsupported Mo nitrides have been attributed to surface defects. The properties of sites associated with the raft-like domains depended on the composition of the material.

The influence of composition on the activity was isolated by comparing catalysts with similar loadings. The activity decreased as the N/Mo ratio increased, particularly for the low-loaded materials, suggesting that the catalytically active sites were associated with nitrogen-deficient domains. Sulfur vacancies have been implicated as the primary reaction sites for organonitrogen and organosulfur molecules on the surfaces of sulfided molybdate catalysts (15). In an analogous way nitrogen vacancies at the Mo nitride surface could be the catalytically active sites. Haddix et al. reported (20) that nitrogen-deficient patches on Mo nitrides were sites for hydrogen adsorption. We noticed that the relative amount of $\mathrm{NH}_{3}$ that was removed when the materials were degassed increased as the loading decreased. This 
corresponds to the materials with the lowest $\mathrm{N} / \mathrm{Mo}$ ratios possessing disproportionately large numbers of $\mathrm{NH}_{3}$ adsorption sites.

The nitrogen deficiency may have been supplemented by other nonmetal atoms. Oxygen and carbon would be available during preparation of the materials or under reaction conditions. These atoms, like nitrogen, satisfy the Hägg rule for Mo based interstitial compounds. The Hägg rule characterizes the ability of nonmetal atoms to reside in the interstices of a metal lattice (21). For many interstitial compounds the metal to nonmetal atomic ratio is set within stoichiometric limits (22); thus one might envision that as the nitrogen content decreases, the oxygen and/or carbon content increases. This implies that the activity increases as the oxygen and/or carbon content increases. While we were not able to determine the oxygen content of the active species, the relative amount of carbon in or on the used catalysts scaled with the activity (Table 4 and Table 6). Combined, the N/Mo and C/Mo ratios for the 8 and $16 \mathrm{wt} \%$ catalysts were similar to those expected for either the face-centered cubic $\left(\gamma-\mathrm{Mo}_{2} \mathrm{~N}_{1-x} \mathrm{C}_{x}\right)$ or the hexagonal $\left(\delta-\mathrm{MoN}_{1-x} \mathrm{C}_{x}\right)$ Mo carbonitride. Here we define the carbonitride as a nitride lattice with partial substitution of nitrogen by carbon. We expect Mo carbonitride to be active for HDN since both the nitride and carbide are exceptional hydrotreatment catalysts $(2,3)$. Incidentally, carbonitrides should produce diffracion patterns nearly identical to those of the related nitrides. The $\mathrm{C} / \mathrm{Mo}$ ratios for the low-loaded materials were significantly in excess of unity. This excessive amount of carbon was probably the result of unreactive carbon build-up at the surface; however, it is possible that a carbonaceous overlayer played a role in the catalysis.

Our picture of the most active species in $\gamma-\mathrm{Al}_{2} \mathrm{O}_{3}$-supported nitrides is that of raft-like domains with the catalytically active sites located around the perimeters. For raftlike domains, the surface area per volume ratio should remain approximately constant as the lateral dimension increases. However, the perimeter length per volume ratio should increase as the domain size decreases. For the supported Mo nitrides, particularly those with loadings of no more than $8 \mathrm{wt} \% \mathrm{Mo}$, we found that the $\mathrm{O} / \mathrm{Mo}$ ratio was approximately constant as the domain size and loading decreased. The activity, however, increased as the domain size decreased. This suggested that oxygen chemisorbed on the entire surface of the domain but catalysis occurred predominantly at the perimeter. We expect sites at the perimeter of these domains to be very different from those on bulk Mo nitride because of the influence of the $\gamma-\mathrm{Al}_{2} \mathrm{O}_{3}$ support. The low N/Mo ratios also suggested that regions near the perimeter were nitrogen deficient perhaps due to the presence of oxygen from the support.

\section{CONCLUSIONS}

A series of $\gamma-\mathrm{Al}_{2} \mathrm{O}_{3}$ supported Mo nitrides were synthesized by reacting supported molybdates with $\mathrm{NH}_{3}$ in a temperature programmed manner. The structures and compositions of the supported species were significantly influenced by the loading and the conditions used to nitride the precursor oxide. We believe that materials with loadings less than that expected for monolayer coverage by the molybdate consisted of highly dispersed, raft-like domains. Higher loadings resulted in the formation of $\gamma-\mathrm{Mo}_{2} \mathrm{~N}$ crystallites.

The pyridine hydrodenitrogenation activities decreased with increasing loading suggesting that HDN was structure-sensitive over the supported Mo nitrides. We interpreted the results in terms of two types of active sites. It appeared that the most active sites were located at the perimeters of the raft-like domains. Lower activity sites were associated with the $\gamma-\mathrm{Mo}_{2} \mathrm{~N}$ crystallites. Finally, we found that the activities of the supported Mo nitrides were superior to that of a commercial Ni-Mo hydrotreatment catalyst and comparable to those of unsupported Mo nitrides.

\section{ACKNOWLEDGMENTS}

We are grateful for the financial support of the Department of Energy (DE-FG22-92PC92537), National Science Foundation (CTS-9158527) and the Shell Oil Company. Mr. Colling also acknowledges fellowship support from the E.I. DuPont Company. We appreciate the assistance of Nedra Degraffenreid in measuring the BET surface areas.

\section{REFERENCES}

1. Choi, J. G., Brenner, J. R., Colling, C. W., Demczyk, B. G., Dunning, J. L., and Thompson, L. T., Catal. Today 15, 201 (1992).

2. Sajkowski, D. J., and Oyama, S. T. in "Symposium on The Chemistry of W/Mo Catalysis, 199th A.C.S. National Meeting, Boston, Massachusetts, April 22-27, 1990," Prepr. Am. Chem. Soc. Div. Pet. Chem.

3. Schlatter, J. C., Oyama, S. T., Metcalfe, J. E., and Lambert, J. M., Ind. Eng. Chem. Res. 27, 1648 (1988).

4. Nagai, M., and Miyao, T., Catal. Lett. 15, 105 (1992).

5. Lee, K. S., Abe, H., Reimer, J. A., and Bell, A. T., J. Catal. 139, 34 (1993).

6. Markel, E. J., and Van Zee, J. W., J. Catal. 126, 643 (1990).

7. Nagai, M., Miyao, T., and Tuboi, T., Catal. Lett. 18, 9 (1993).

8. Abe, H., and Bell, A. T., Catal. Lett. 18, I (1993).

9. Deo, G., and Wachs, I. E., J. Phys. Chem. 95, 5889 (1991).

10. Wang, L., and Hall, W. K., J. Catal. 77, 232 (1982).

11. Cullity, B. D., "Elements of X-Ray Diffraction." Addison-Wesley, Reading, MA, 1978.

12. Erdtmann, G., "Neutron Activation Tables." Verlag Chemie, New York, 1976.

13. Parekh, B. S., and Weller, S. W., J. Catal. 47, 100 (1977).

14. Zmierczak, W., MuraliDhar, G., and Massoth, F. E., J. Calal. 77, 432 (I982).

15. Massoth, F. E., Adv. Catal. 27, 265 (1978). 
16. Volpe. L., and Boudart. M., J. Solid State Chem. 59, 332 (1985).

17. Scheffer, B., Arnoldy, P.. and Moulijn. J. A., J. Catal. 112, 516 (1988).

18. Volpe, L., Oyama, S. T., and Boudart, M., in "Preparation of Catalysts, III" (G. Poncelet, P. Grange, and P. A. Jacobs, Eds.), p. 147. Elsevier, Amsterdam, 1983.
19. Colton, F. A., and Wilkinson, G.. "Advanced Inorganic Chemistry." Wiley, New York, 1988.

20. Haddix, G. W.. Reimer. J. A., and Bell, A. T., J. Catal. 108, 50 (1987).

21. Hägg, G., Z. Phys. Chem. B 12, 33 (1931).

22. Goldschmidt, H. J.. "Interstitial Alloys." Plenum, New York, 1967. 